\title{
Nursing skill mix and patient outcomes
}

\section{Jack Needleman}

Correspondence to

Dr Jack Needleman, Department of Health Policy and

Management, UCLA Fielding School of Public Health, 650

Charles E. Young Dr. S., Room 31-236B CHS, Los Angeles, CA 90095-1772, USA; needlema@ucla.edu

Accepted 12 December 2016 Published Online First 29 December 2016

\section{SLinked}

http://dx.doi.org/10.1136/ bmjqs-2016-005567

\section{CrossMark}

To cite: Needleman J. BMJ Qual Saf 2017;26: 525-528.
In hospitals, the nursing staff typically represent the largest single element of cost, and nursing is frequently treated as a cost centre rather than a core service line. Efforts to contain hospital costs often involve cutting nursing care, reducing the number of nurses or replacing some professional nursing staff with staff such as licensed practical nurses, nurses' aides and other assistive personnel.

Substantial evidence from studies in the USA, Europe and other countries relates lower nurse staffing and higher nurse workloads to adverse patient outcomes such as mortality, infections, falls and longer lengths of stay. Longer stays, which increase hospital costs, may result from increased adverse events lengthening admissions or delays in care due to nurses being unable to complete their work or prepare patients for discharge. ${ }^{1-13}$

The consequences of relying more heavily on staff less educated than the professional nurse, using a lower skill mix, remain less well studied. Studies from the USA and Canada, often focusing on the mix of professional nurses (registered nurses) and licensed practical nurses have consistently found lower skill mix to also be associated with higher rates of adverse outcomes and longer length of stay. ${ }^{714-17}$

Aiken et $a l^{18}$ examine the association of skill mix with mortality, patient ratings of hospitals, nurse-reported frequency of adverse patient outcomes and nurse job dissatisfaction and burnout, using data from hospitals in six European countries. They find substantial variation across medical-surgical units in the proportion of professional nurses among direct care nursing personnel (which include professional nurses, licensed practical nurses, nursing assistants and other job categories that vary across their six country sample) and that this variation in skill mix is associated with patient mortality, patient perceptions of care and nurse judgements of quality and frequency of adverse outcomes.

A strength of this study is the variety of measures examined and data sources used. These include 30-day inpatient mortality derived from administrative record sets, hospital ratings from patient surveys and three related sets of measures from surveys of nurses: nurse perceptions of quality of the unit and hospital, nurse estimates of the frequency of adverse patient events and nurse burnout and job dissatisfaction.

The authors found that both nurses and patients reported quality problems at significant rates. Over half the patients surveyed give their hospital a less than excellent rating. The average percentage of nurses rating unit quality as fair or poor was $22 \%$, and $18 \%$ would not recommend their hospital to friends and family. Nurses' assessments that adverse events occurred several times a month or more frequently, varied from $9 \%$ for pressure ulcers to $23 \%$ for urinary tract infections. Nurse burnout and dissatisfaction rates were high.

In analyses that controlled for country and a variety of relevant hospital and patient characteristics, richer skill mix was associated with lower odds for each of their measures - the odds of death, low hospital ratings from patients and poor safety grades, among other undesirable outcomes. The ORs for the changes in these measures associated with improving skill mix by 10 percentage points ranged from 0.80 to 0.93 . Because most of the authors' measures come from their nurse survey, one might argue that one expects responses on the survey to be correlated as respondents let general attitudes towards quality of care influence individual item responses. However, the similarity of the results of the analyses of nurse-derived measures, patient-reported quality and mortality lends strength to the conclusion that there is a consistent association between skill mix and quality of care. 
The authors note important limitations in the data and methods. To their limitations, I would add that relying on surveyed nurses to establish overall census and the ratio of professional nurses to other nursing staff is imprecise. Nurse reporting of unit staffing and census was adopted because of limitations of administrative data to estimate staffing. ${ }^{19}$ This is an extension of the method used in the US studies, where nurses have been asked for their individual workload on their last shift. ${ }^{1}$ But relying on the surveyed nurses to be aware and report their own patient load and the overall census and count of professional nurses and other nursing staff has inherent imprecision. Patient census on a shift can change with admissions, discharges and transfers of patients and nursing staff counts can also change as nurses join or leave the unit to respond to staffing needs on the unit or elsewhere in the hospital. Beyond this, the measure relies upon the surveyed nurse to be knowledgeable not only about their own workload but also overall staffing and census of the unit. Methods for assuring the accuracy of the reported counts not directly related to the nurses' assigned workload are not described. An assessment of the precision of the measure is warranted.

A limitation the authors note but I would emphasise is the variety across countries in the training and qualifications of unit staff counted as direct care nursing personnel other than professional nurses. The range of education and training among the non-professional nurse members of the nursing staff is less standardised across countries than for professional nurses. The authors seek to control for this variation by including country-level fixed effects, but these will also control for unmeasured variation in hospital care other than the qualifications of staff who are not professional nurses. Stratified analysis by country, while it might suffer from low power for some countries, would provide information on whether the relationship of skill mix and outcomes is consistent across countries or whether the differences in staff qualifications and training or organisation of work across countries result in different magnitudes for the associations of skill mix and outcomes.

Notwithstanding these limitations, this is a solid study. It adds an important cross-national perspective to the US studies of skill mix. It confirms the key findings of the prior work that staffing that relies on non-professional nurses for a substantial component of direct patient care can put patients at risk for a wide range of adverse outcomes. It extends the prior work in its finding that the limitations on care register on patients and influence their ratings of hospitals.

Hospital, payer and policy makers' goal in replacing professional nurses with less trained personnel is to reduce labour costs. As Aiken et al observe 'hospital nurse staffing is a frequent target for budget reduc- introduction of lower skilled and less educated nurse substitutes like "nursing associates".

The societal costs of these decisions can be high, as appropriate valuing the excess mortality would demonstrate, but societal costs are not borne by the hospital. What is borne by the hospital, to the extent it is paid on an overall budget or per admission basis, are costs associated with longer lengths of stay, the costs of the complications and end-of-life care associated with increased patient deaths, the costs of adverse events such as the pressure ulcers, falls with injury and urinary tract infections associated in this study with low skill mix (as well as outcomes associated with low skill mix in other studies), and the costs to hospitals of nurse turnover due to burnout and job dissatisfaction. A critical question for hospital management is whether the costs of the adverse events and turnover exceed the labour cost savings of employing a less skilled mix of nursing staff.

This question cannot be answered directly from this study. The change in counts or rates of adverse events (except for mortality) cannot be estimated because of the reliance on nurse assessments rather than direct measurement of the frequency of the adverse events and dichotomisation of these measures. Without these counts, costs savings associated with reducing adverse events cannot be calculated.

Business case analysis of the additional cost of more skilled nurses and the offsetting cost savings from shorter stays and lower adverse event rates has been conducted using the US studies. A 2006 Health Affairs article used a microsimulation approach to simulate the effect of changing skill mix on changes in length of stay, and rates of failure to rescue, and four other adverse events. ${ }^{20}$ It estimates the costs of improving the skill mix of the nurses and the cost savings from lower length of stay and reduced adverse events. A 2014 Medical Care study directly regresses cost per admission on a robust patient risk adjuster and the hospital staffing levels and skill mix. ${ }^{21}$ Both studies find a skill mix with a higher proportion of professional nurses are cost saving for hospitals, with the cost offsets of lower adverse events and shorter length of stay paying for the additional costs of the richer skill mix. The Health Affairs article also finds that length of stay is more sensitive to staffing levels than it is to skill mix, perhaps reflecting delays in care due to short staffing. In contrast, adverse events such as urinary tract infections and hospital-acquired pneumonia show greater sensitivity to skill mix, possibly reflecting the role of education and training in detecting and preventing complications in hospitalised patients.

The results reported by Aiken et $a l^{18}$ strongly suggest that the conclusions from the US studies would apply to European hospitals-higher nursing skill mix lowers total hospital costs. So why does the interest in substituting professional nurses with lower 
Payment is a factor in some countries. Where hospitals are paid based on charges or per diem costs, longer stays due to delayed care or adverse events enhance revenue. Under these payment systems, there is an incentive to minimise costs of production, not costs of avoidable or delayed care. But per case or global budget payment should encourage consideration of total costs of care, including the cost-offsets associated with increased expenditures on staffing.

Another reason for the persistent interest in substituting lower skilled personnel is that the work of nurses is not well understood. The most visible work of nurses is task oriented-delivering ordered care, taking vital signs, helping patients eat, ambulate, toilet and so forth. As a result, it may seem plausible to administrators, payers and policy makers that less educated and lower cost personnel can substitute for professional nurses in this work. While these visible bedside tasks constitute important components of nurses' work, they also represent an incomplete view of that work.

Nurses' work is complex, and cognitively and managerially demanding. While doing the visible task work, nurses are also assessing and monitoring their patients, determining whether their patients are at risk for falls, pressure ulcers and other complications and whether patients are progressing as expected or developing complications. Based on these assessments, nurses are expected to initiate appropriate nursing interventions or call for consultations. Nurses monitor pain and take action to control it. They provide patient and family education, prepare patients and their families for self-care after discharge and provide psychological support for patients dealing with serious illness. Nurses play critical roles in team-based care, backstopping physicians and pharmacists by ensuring medications and other ordered care are correctly prescribed and administered, and often serving as the principal coordinators of care and advocates for their patients. And these activities are carried out for each patient by nurses responsible for four, five, six or more patients at the same time, a situation that imposes substantial managerial demands on frontline nurses. $^{22}$

The full scope of nurses' work has been the subject of increased articulation in the nursing literature, ${ }^{23-25}$ but is not yet fully appreciated by those outside the profession. The more complex, cognitive and managerial activities of nurses, because they are often done concurrently with the task-oriented work of nurses, often go unobserved and unappreciated. Studies of the association of skill mix, such as the study by Aiken et al, and earlier studies of skill mix and nurse workloads and patient outcomes, provide strong evidence that when nursing staffs do not have the time or training to carry out their work, patient safety and patient care are put at risk. Recognition of payers and the public, and acting on this understanding, is critical to assuring the effective, safe and reliable delivery of healthcare.

Competing interests None declared.

Provenance and peer review Commissioned; internally peer reviewed.

\section{REFERENCES}

1 Aiken LH, Clarke SP, Sloane DM, et al. Hospital nurse staffing and patient mortality, nurse burnout, and job dissatisfaction. JAMA 2002;288:1987-93.

2 Aiken LH, Sloane DM, Bruyneel L, et al. Nurse staffing and education and hospital mortality in nine European countries: a retrospective observational study. Lancet 2014;383:1824-30.

3 Cho E, Sloane DM, Kim EY, et al. Effects of nurse staffing, work environments, and education on patient mortality: an observational study. Int J Nurs Stud 2015;52:535-42.

4 Griffiths P. Staffing levels and patient outcomes. Nurs Manag (Harrow) 2009;16:22-3.

5 Kane RL, Shamliyan TA, Mueller C, et al. The association of registered nurse staffing levels and patient outcomes: systematic review and meta-analysis. Med Care 2007;45:1195-204.

6 Liang YW, Chen WY, Lee JL, et al. Nurse staffing, direct nursing care hours and patient mortality in Taiwan: the longitudinal analysis of hospital nurse staffing and patient outcome study. BMC Health Serv Res 2012;12:44.

7 Needleman J, Buerhaus P, Mattke S, et al. Nurse-staffing levels and the quality of care in hospitals. N Engl J Med 2002;346:1715-22.

8 Needleman J. Nurse staffing: the knowns and unknowns. Nurs Econ 2015;33:5-7.

9 Needleman J, Buerhaus P, Pankratz VS, et al. Nurse staffing and inpatient hospital mortality. N Engl J Med 2011;364:1037-45.

10 Shekelle PG. Nurse-patient ratios as a patient safety strategy: a systematic review. Ann Intern Med 2013;158(Pt 2):404-9.

11 Tourangeau AE, Doran DM, McGillis Hall L, et al. Impact of hospital nursing care on 30-day mortality for acute medical patients. J Adv Nurs 2007;57:32-44.

12 Twigg DE, Gelder L, Myers H. The impact of understaffed shifts on nurse-sensitive outcomes. J Adv Nurs 2015;71:1564-72.

13 Zhu XW, You LM, Zheng J, et al. Nurse staffing levels make a difference on patient outcomes: a multisite study in Chinese hospitals. J Nurs Scholarsh 2012;44:266-73.

14 Blegen MA, Goode CJ, Spetz J, et al. Nurse staffing effects on patient outcomes: safety-net and non-safety-net hospitals. Med Care 2011;49:406-14.

15 Cho SH, Ketefian S, Barkauskas VH, et al. The effects of nurse staffing on adverse events, morbidity, mortality, and medical costs. Nurs Res 2003;52:71-9.

16 Estabrooks CA, Midodzi WK, Cummings GG, et al. The impact of hospital nursing characteristics on 30-day mortality. Nurs Res 2005;54:74-84.

17 Unruh L. Licensed nurse staffing and adverse events in hospitals. Med Care 2003;41:142-52.

18 Aiken LH, Sloan D, Griffiths P, et al. Nursing skill mix in European hospitals: association with mortality, patient ratings, and quality of care. BMJ Qual Saf 2017;26:559-68. 


\section{Editorial}

19 Sermeus W, Aiken LH, Van den Heede K, et al. Nurse forecasting in Europe (RN4CAST): rationale, design and methodology. BMC Nurs 2011;10:6.

20 Needleman J, Buerhaus PI, Stewart M, et al. Nurse staffing in hospitals: is there a business case for quality? Health Aff (Millwood) 2006;25:204-11.

21 Martsolf GR, Auerbach D, Benevent R, et al. Examining the value of inpatient nurse staffing: an assessment of quality and patient care costs. Med Care 2014;52:982-8.
22 Ebright PR, Patterson ES, Chalko BA, et al. Understanding the complexity of registered nurse work in acute care settings. J Nurs Adm 2003;33:630-8.

23 Kitson A, Conroy T, Wengstrom Y, et al. Defining the fundamentals of care. Int J Nurs Pract 2010;16:423-34.

24 Kitson AL, Muntlin Athlin A, Conroy T. Anything but basic: nursing's challenge in meeting patients' fundamental care needs. J Nurs Scholarsh 2014;46:331-9.

25 Needleman J. The economic case for fundamental nursing care. Nurs Leadersh (Tor Ont) 2016;29:26-36. 